\title{
Disseminating the right information to the right audience: cultural determinants in the use (and misuse) of rankings
}

\author{
Leon Cremonini · Don Westerheijden · Jürgen Enders
}

Received: 5 December 2006/Accepted: 3 April 2007/Published online: 5 May 2007

(C) Springer Science + Business Media B.V. 2007

\begin{abstract}
Rankings and league tables, or Report Cards (RCs), of Higher Education Institutions have become a global phenomenon. Their purpose, it is claimed, is to help "student-consumers"' make informed decisions. Yet the degree to which RCs succeed in helping students in their college choice is disputed. Even though RCs are intended for all, which information is sought and how it is used may differ between potential students hailing from different social, economic and cultural backgrounds. In particular, RCs may neglect certain cultural determinants that influence students' college choice behaviour. The article reviews the literature on the cultural determinants of college choice and especially the use of RCs in the ambit of cultural determinants. In the United States, possibly because of evident educational gaps between ethnic groups in society, the issue of cultural perceptions in college choice has been addressed, albeit scantly. In Europe, this field of study is virtually non-existent, despite increasing indications that second and third generation immigrants still lag behind in terms of higher education participation and graduation rates.
\end{abstract}

Keywords College choice - Consumer information - Culture $\cdot$ Higher education · Information processing $\cdot$ Ranking $\cdot$ Report card $\cdot$ Students

\section{Introduction}

Interest in what factors shape people's choices is not recent. Extensive research has been conducted in the fields of sociology, psychology and economics to understand, and often

L. Cremonini $(\bowtie) \cdot$ D. Westerheijden $\cdot$ J. Enders

Centre for Higher Education Policy Studies (CHEPS), University of Twente,

P.O. Box 217, 7521 PL Enschede, The Netherlands

e-mail: 1.cremonini@utwente.nl

D. Westerheijden

e-mail: d.f.westerheijden@utwente.nl

J. Enders

e-mail: j.enders@utwente.nl 
influence, the way we make our decisions. More recently, it has been emphasised that "culture" plays an important role in the decision-making process. Hence, it is argued, factors other than mere economic advantage or individual psychology ought to be taken into account when studying the underpinning reasons for making one choice instead of another. Marketing studies, for instance, have tried to understand how "culture" may impact buyers' behaviours (e.g. will a successful car commercial in the United States have a similar effect on Japanese purchasing behaviour?) (Polyorat \& Alden, 2005).

In recent years, higher education, too, has been discussed as a marketable commodity by researchers and policy makers (Lloyd, 2005). Its massification has led many to believe that students are "customers" in a system where Higher Education Institutions (HEIs) compete fiercely to attract the brightest of them (Ibid.). Students have expectations of their own. In their view higher education should yield meaningful advantages, for example higher salaries upon graduation, a gratifying on-campus life or simply a rewarding professional future.

Hence, consumer information tools for higher education, such as university and programme rankings, or Report Cards ${ }^{1}$ (RCs), have burgeoned. It has been contended both by commercial publishers of rankings and by public policy-makers that, like for the sale of commercial goods, the chief role of such RCs is to help consumers make informed decisions. Hence, RCs should help students in their college choice process. ${ }^{2}$

Yet, unlike marketing or management studies, college choice literature pays little attention to the possible consequences of "culture" on students' information processing during their choice processes (Nora, 2004; Zimbroff, 2005), even in the presence of increasingly multi-cultural societies. ${ }^{3}$ Culture can be considered broadly as a system of shared beliefs, values, customs, behaviours, etc., of specific groups in society (Kroeber \& Kluckhohn, 1952). These values and beliefs affect the behaviours of the groups' members, and their interpretation of other people's behaviours (Spencer-Oatey, 2000). Even though these groups are often identified with particular ethnic groups, existing studies on college choice tend to relate ethnic diversity with socio-economic diversity. Issues more directly associated with the "cultural interpretation"' of information are typically neglected. RCs, specifically, fail to incorporate cultural aspects in the information they seek to provide and in the way they present it. Interestingly, while RCs are criticised on a number of methodical grounds (which largely have be amended in some of the better-designed, recent RCs), critics fall short on voicing "culture", as a missing element.

The present paper extends the debate about RCs to the cultural determinants of college choice and how they may influence RCs' ability to reach out to different audiences in society. The target population of RCs are those students who, having made up their mind on enrolling in higher education, need to decide which institution is best for them. The following pages will not provide definite solutions to the array of issues stemming from

\footnotetext{
1 The term "Report Card"' is preferable to "ranking", because as recent literature has emphasised and as is explained in this article, what is needed to inform (prospective) students is an overview of elements that help them make a reasoned choice, which is multi-dimensional and subjective. An RC pretends to do no more than that-give information about a number of elements or dimensions. "Ranking'" on the other hand is inherently a uni-dimensional and often "objective", (in the sense of: same for all) list of higher education institutions or study programmes ordered from "best" to "worst".

2 This is evident in claims made in all commercial rankings (e.g. USNWR, the Guardian, The Times, CHE, etc.)

3 The increase of multi-culturalism may affect highly developed countries across the world, but for practical reasons we will limit ourselves to considering the consequences for report cards on higher education in Europe.
} 
cultural differences, information processing, and college choice (the reader will not find step-by-step instructions for the creation of "the perfect university RC'), but will raise the reader's awareness on the potential role of "culture" in the processes. The paper contends that, also in light of the insights provided by similar studies in other fields, further study would be beneficial in widening the outreach and effectiveness of RCs.

The remainder of this paper is divided into four sections. The "College choice models" section describes known models of college choice; the "Current critiques of rankings" section outlines some of the key critiques of rankings and suggests that "cultural aspects", have largely been neglected in these arguments; the "Culturally based perceptions..." section broadens the debate to discuss culturally based perceptions of decision making in general, and of college choice in particular. This section describes possible implications of cultural diversity on the use and interpretation of the information provided in RCs', and puts forward questions as on how to develop rankings that members of different cultures may use more effectively. In the "Concluding remarks" section, we offer some concluding remarks.

\section{College choice models}

College choice is usually considered a three-stage process involving, analytically, successive decisions on collecting, evaluating and acting on information about higher education institutions ("colleges"), which finally lead students to enrol in a particular higher education programme. While different authors posit slightly different stages, broadly they involve the decision to want to attend college, a filtering stage to narrow down the number of alternative colleges and programmes to be considered, and the final application and enrolment (the perspective of the higher education institution, which in different ways in different countries also plays an active role in attracting students, is not considered here).

Traditional college choice models can be clustered in three types that specify factors leading to enrolment decisions: sociological, econometric, and combined (Hossler, Schmit, \& Vesper, 1999; Jackson, 1982). These models are described below.

Econometric models of college choice

Economists focus on the "relationship between the attributes of goods (college and job characteristics) and individual choices, and these interests lead to models that emphasise the interaction between preferences, largely a function of aspiration, and constraints" (Jackson, 1982). Economic models are based on the idea that students perform a rational cost-benefit analysis to maximise the utility of college attendance. Under the assumption of perfect information, these models focus on how students with certain characteristics differ in variables that are important when they choose college.

Within the econometric literature, two kinds of models can be found. The first type concentrates on the choice between participating in higher education vs. pursuing other alternatives, such as military service or immediate employment (Bishop, 1977; Fuller, Manski, \& Wise, 1982; Kohn, Manski, \& Mundel, 1976; Manski \& Wise, 1983). The second type of model, addressed by authors such as Kohn et al. (1976) and Chapman (1984), involves the choice of a particular institution and programme. According to both groups of studies, influencing factors include tuition, net tuition (tuition minus financial support), living costs, foregone earnings (in some models), expected future earnings, 
family background characteristics (income, educational level, occupation), average ability, and sociological factors such as aspirations of neighbourhood peers or parents' educational background.

\section{Sociological models of college choice}

Sociological models of college choice (also known as "status-attainment" models) relate to individuals' aspiration to attend college (Jones, 2002). These models suggest that socialisation processes, family conditions, interactions with peers, school environments, etc. have a significant impact on students' college choices. It is assumed that behavioural variables, such as academic performance or how leisure time is spent, interact with background variables such as parental education and occupational status. Boyle (1966), and Alwin and Otto (1977), amongst others, suggest several factors that might influence students' enrolment decisions. These factors include family socio-economic background, academic ability, the influence of significant others, high- school performance, educational aspirations, motivation (viewed as a psychological factor), and high school characteristics. The main difference with the economic models is that these models involve a more interactive process between variables defining the social context and individual student characteristics. Interestingly, even though extensive research has been conducted using sociological models, research has failed to include systematically students from all ethnic (and cultural) backgrounds (Jones, 2002).

\section{Combined models of college choice}

Since both the status-attainment and economic models have been unable to capture satisfactorily the process of college choice, various "combined models", have been developed over the years. According to Hossler, Braxton, and Coopersmith (1989), combined models can be classified as "three-stage models" or "multi-stage models". Furthermore, Hossler et al. (1989) suggest that combined models attempt to identify the factors that affect decision-making processes from a policy analysis perspective. In other words, they try to describe the economic and social forces affecting individual decision making to find opportunities for intervention in the process of the students' choices. In addition, recent studies using behavioural economics to gain a more complete understanding of student choice, theoretically argued that individuals cannot be assumed to engage in purely rational decision-making because their perceptions of financial signals are filtered by psychological phenomena such as loss aversion, reference levels, mental accounting and inter-temporal choice. Empirically, this type of research has shown that those perceptions differ according to socio-economic and cultural background (Vossensteyn, 2005). While they do not represent the full array of existing combined models, four major models include Jackson (1982), Hanson and Litten (1982), Chapman (1984), and Hossler and Gallagher (1987).

The Jackson Model, also known simply as the "Combined Student Choice Model', posits three stages. In Stage I, called "preference', prospective students begin to form concrete plans concerning pursuing college education. Sociological research shows that academic achievement strongly correlates with educational aspirations, and academic ability, family background and significant others play a key role. During Stage II (exclusion), students begin to gain economic information on several HEIs/programmes (e.g. regarding costs, location, academic quality, etc.). This information is used to develop 
a group of potential colleges from which to choose one to enrol. Finally, in the evaluation stage, the remaining institutions are assessed on the basis of their characteristics. Jackson (1982) indicates that this stage is based on a cost-benefit analysis.

The Chapman Model uses both an individual and institutional perspective, suggesting that student characteristics (socio-economic status, scholastic aptitude, educational aspirations and academic performance) and external influences (significant others, college characteristics and college marketing efforts) interact to form a student's general expectation of college life.

Third, Hossler and Gallagher (1987) propose a developmental model in which "students move towards an increased understanding of their educational options as they seek a post-secondary educational experience', (Jones, 2002). The model provides a three-stage framework which puts the individual student in the centre: the predisposition stage (decision to go to college), the search stage (learning about and comparing institutions) and the choice stage (completing applications and actually choosing an institution).

Hossler and Gallagher's approach is primarily sociological, relying on background characteristics. To designate the whole cyclical process of gathering information, processing it, and making decisions to reduce uncertainty, their model uses the term "'information processing", which, in turn, takes place in a particular social setting labelled "social capital" of students. The social capital includes student background characteristics (e.g. ability) and family factors (e.g. parents' income and education), as well as preferences and attitudes transmitted to children, the way in which parents help defining the future of their children, for example reading and encouragement of critical thinking and college attendance, etc. At the same time, the concept of social capital reckons with the interaction among the three major socialising agents of students: the family, the peer group and the school.

Finally, we mention one of the most elaborate models, developed by Hanson and Litten, the so-called 'College Attendance/Choice Model', According to this model, student choice is a continuing process, which encompasses the phases of (1) aspiration (2) exploration (i.e. starting and conducting the search process), and (3) application/matriculation. The authors identified an array of variables influencing the whole college choice process or elements of it, including:

- Background characteristics: parental income and education, race, gender

- Personal characteristics: academic ability, class rank, self-image

- High school characteristics: social composition, programs, curriculum

- College characteristics: costs, size, programs, timeliness in responding to questions

They also included public policies, such as financial support, as intervening variables. Chart 1 shows a slightly modified version of the Hanson and Litten's (1982) model (see also Vossensteyn, 2005). The chart depicts the student choice process and its most important variables.

\section{Current critiques of rankings}

The prior section has briefly outlined known models of college choice, which fall within the realm of decision-making processes more generally. It is noteworthy, however, that the issue of "culture" has not been looked into in any depth. In addition, it is remarkable that rankings, which purport to assist prospective students in their college choice processes, 


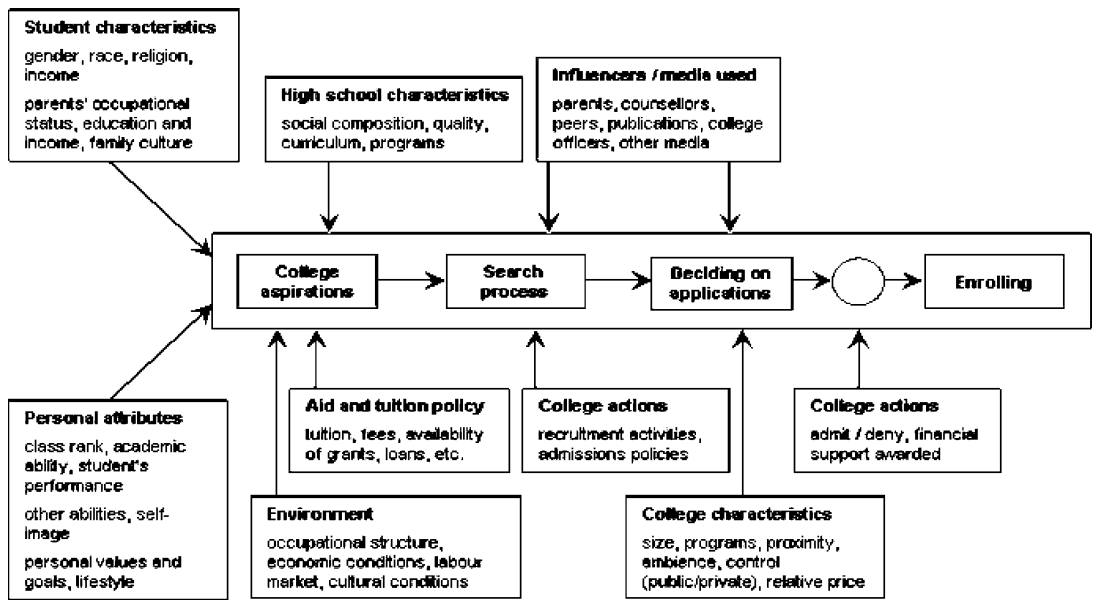

Chart 1 The student choice process and its most important variables. Source: Hanson and Litten (1982), adapted by Vossensteyn (2005)

also show little attention to cultural aspects. Given an increasingly multicultural world, the question arises as to whether cultural differences ought to be included in the discussion to a greater extent.

This section outlines some of the key critiques rankings face today. As can be seen below, the lack of references to cultural aspects is apparent. Not only do the rankings not address this issue, but the critiques to the rankings do not consider this a problem either. In fact, critiques focus almost exclusively on issues related to the indicators (their value in reliability, validity, etc.) and the universities' reactions.

First, the indicators themselves are often deemed the key weakness of ordinal ranking systems. Indicators should have the desirable measurement properties of validity (does the indicator measure what it purports to measure?), reliability (does it do so in a consistent/ error-free fashion?), and comparability (can it be interpreted in a similar way across different kinds of programmes or institutions?) (Bowden, 2000; Clarke, 2002; Dill \& Soo, 2005; Provan \& Abrecromby, 2000). Yet, rankings often fail to satisfy these properties. Since rankings' alleged raison d'être is to help consumers (prospective students) make informed decisions on their educational future by providing comparable information on the quality of HEIs, faults in the indicators effectively invalidate the exercise. Rankings, then, appear more like "beauty contests" than comparative quality assessments. In this respect, it has been suggested that there might be a role for government to assure adequate, namely valid, reliable and comparable, consumer information on higher education (Dill \& Soo, 2005).

Second, even the rankings' self-stated role of informing student choice is met with reservations (Eccles, 2002). It has been suggested that “(...) the majority of university bound students in the U.S. do not regard the league tables as a very important factor in their selection process (...)"' (Provan \& Abrecromby, 2000, p. 4). Others maintain that rankings are likely to be more useful where students are burdened with a high cost for their education (Ibid.), which might explain the commercial success of university rankings in the U.S.. Substantiating such claims, Usher and Savino (2006, p. 3) recall that "(...) copy-cat ranking systems began popping up all over the world, usually shortly after the introduction of-or rapid increase in-tuition fees.' Finally, some think that report cards, far from 
providing useful guidance to all prospective students, are made for the "strong applicant", and, thus, reflect student choice rather than informing it (Sarrico et al. cited in Bowden, 2000).

Third, in the increasingly competitive higher education market, universities consider it ever more important to be ranked and remain at the top of the list. This, however, is not necessarily an expression either of quality education or of sincere interest in student learning. Several sources have highlighted that rankings can have a negative effect of university policy: universities will go to great lengths to improve their ranks, "gaming the rankings" to be rated well (Avery, Glickman, Hoxby, \& Metrick, 2004; Bowden, 2000; Dill \& Soo, 2005). For example, institutions can improve their standings by inflating their grades or increasing the selectivity of their admission policies. Such practices can result in denying access to qualified students, or in institutions becoming reluctant to invest (i.e. risk) on students who might have potential that is not captured in commercial measures (Vaughn, 2002). Furthermore, given the wealth of ranking systems, each university will highlight those rankings where it is rated best, without mention of where it is not rated so well.

Last, and in addition to much of the literature criticising RCs, it has been repeatedly stressed that the rankings are almost entirely input-driven, even though a more process and output approach would be preferable. As in the old discussion about performance indicators for quality assurance, what is measurable seems to be incorporated into the rankings, rather than what is valid (for an early example: Goedegebuure, Maassen, \& Westerheijden, 1990). In analogy with the economic and social models for college choice, indicator models-even before we consider cultural aspects-(should) model how students perceive their study (also: Vossensteyn, 2005). The economic model in this case is an investment model, viewing study as a means to gain a job, income, etc.; this requires information about the output of higher education (graduates, time to degree, employment data, etc.). If necessary, some input information could be used as a (distant) proxy variable, such as the qualifications of teaching staff. The sociological model finds its analogy rather in a consumption model of study, in which direct costs of studying play a role (e.g. tuition) but also less tangible costs and benefits (such as pleasant study atmosphere, nice campus or city). Input information that plays a role in such a model could be data about student facilities. The point of this digression was to show that input information has only limited value. Process and especially output indicators would be more appropriate to assess the quality of HEIs. Although ranking systems wish to reframe higher education as a consumer good (Guarino, Ridgeway, Chun, \& Buddin, 2005), they generally fail to assess it by outputs. Even though, in an increasingly globalised world, HEIs are likely to compete to provide students with tangible results in the form of learning outcomes, studies on how to approach this problem are still in their infancy (Klein, Kuh, Chun, Hamilton, \& Shavelson, 2005).

\section{Culturally based perceptions of decision-making and college choice}

If we look beyond college choice (i.e. deciding where to apply), equity in access to higher education remains a reason of concern. In the Netherlands, for example, differences in enrolment between western and non-western students are still apparent. Data from the Dutch Central Bureau of Statistics (CBS) indicate that, despite a substantial increase in non-western population aged 19-24 during the period 1995-2002 (over 28\%), their en- 
rolments at university-level education in the same period stalled (less than $1 \%$ increase). Looking more specifically at the second generation, while they doubled in population, they actually decreased in enrolments (unlike their Dutch counterparts). More recent CBS data (for the period up to 2006) show that enrolments have increased also among non-western students, but they tend to choose the lower-prestige institutions. Enrolment of non-western students rose from $5.3 \%$ to $13.1 \%$ of total enrolments in non-university institutions or $147 \%$ increase, and from $6.0 \%$ to $11.4 \%$ in the universities for a $90 \%$ increase (CBS 2007). To what extent this differential enrolment is determined by socio-economic or cultural factors, is not recorded in the statistics and needs further research.

As for college choice, studies on ethnic differences are present, but the dimension we wish to add refers more specifically to issues related to "culture" and its impact on decision-making processes (including college choice). As was mentioned in the introduction, culture is a system of shared beliefs, values, customs, behaviours, etc., which affect the behaviours of different groups in society (often identified with particular ethnic groups). Typically, existing studies on college choice relate ethnic diversity with socioeconomic diversity but ignore issues more directly associated with the "cultural interpretation" of information.

Given the limited sources in college choice literature, it is useful to gain insight into other fields of study to assess whether culture plays a role and what that role might be. This background will help identify aspects and indicators for the creation of "culturally sensitive" RCs. The next few paragraphs will look into research on decision-making not directly related to the specific context of college choice, and marketing strategies. ${ }^{4}$ At the same time, speculations will be made on how this knowledge baggage fits in the RCs discourse.

The process of decision-making, especially in the management field, has been a topic of study for much of the post-war era. As early as 1944, Neumann and Morgenstern had developed the so-called "expected utility model". Other models and concepts followed over time, for example the idea of "economic man" vs. "administrative man" (March \& Simon, 1958) or, recently, “emotional man" vs. "action man”' (Schramm-Nielsen, 2001). Decision processes (including college choice), are affected by cultural differences. These cultural differences are not salient only between western and non-western societies. Often, they are evident between seemingly "close" cultures. For example, the above-mentioned model of "emotional man" vs. "action man" developed by Schramm-Nielsen (2001) applies to the different managerial styles adopted in France and Denmark. Moreover, international marketing research has studied the varying impacts of advertising on socalled "individualist cultures" and "collectivist cultures". "Individualist' cultures are generally typified by a social orientation where individual autonomy and independent selfconstrual prevail. "Collectivist', cultures, on the other hand, are characterised by interdependent self-construal (Hofstede, 2003). These attributes are believed to affect cognition and to shape people's modes of thinking. For example, Kühnen, Hannover, and Schubert (2001) contend that, while an independent self-construal coincides with the tendency to process stimuli unaffected by the context in which they appear, interdependent selfconstruals facilitate context-bounded thinking (i.e. processing stimuli by paying attention to their relation to the given context). It is, thus, reasonable to expect that consumers' responses to ads' stimuli (such as humour, theme persuasiveness etc.) and their purchasing

\footnotetext{
${ }^{4}$ RCs can be fruitfully compared to advertising (especially comparative advertising) since both give information about alternative options, and both aim to aid choice amongst those options.
} 
decisions are also influenced by these cultural factors (Polyorat \& Alden, 2005). Consequently, advertising themes and presentations generally differ between cultures.

The role of independent vs. interdependent self-construal is deemed particularly relevant for consumers' brand attitudes when it comes to comparative advertising:

"Ads in Western cultures tend to use themes related to individualism, competitiveness, and comparisons between brands, whereas ads in East Asian cultures tend to use status symbols and indirect expression. It may be that Asian brand managers are reluctant to cause a competitive brand to "lose face" (...). Losing face is a critical issue in collectivist cultures", (Ibid., p. 2).

In other words, the information presented in advertisements should be "tailored" to its cultural audience, if it is to be effective.

Other researchers have looked at cross-cultural differences in decision-making style, confidence, and conflict resolution. For example, tactics of conflict resolution in individualistic societies are far more assertive whereas in collectivist societies there is a preference for "avoidance tactics" (Ohbushi, Fukushima, \& Tedeschi, 1999). Mann et al. (1998) further surmise that decision-making for collectivist cultures, such as East Asia, is primarily a social process. For individualist cultures (e.g. Western), however, it is mainly a cognitive and conceptual process. Accordingly, collectivist societies tend to procrastinate decisions because they depend on the support of the group to a greater extent than individualists do. Decision self-esteem is also, unsurprisingly, lower in collectivist societies than in individualist ones, because "(...) the person is reinforced for contribution to and support for group decision making", (Mann et al., 1998, p. 329).

Ostensibly, the issues mentioned above also apply to that particular decision-making process that is college choice. Yet, while

"early investigations in the area of college choice revealed that students whose values and beliefs fit with that of an institution were satisfied with their choice and ultimately persisted, (...) the convergence of institutional (college) information with student needs, values, and interests for the purpose of selecting a college is an area in the college choice theory that is less understood" (Nora, 2004, pp. 181-182).

Most studies have focused on college access and choice from a socio-economic standpoint (e.g. including data on income levels, as well as (individual) academic abilities or predisposition), while research on aspects related to cultural determinants of college choice and the interpretation and use of college information by diverse populations is scant. In the U.S., it has been suggested that potential college goers of Latino or African American descent might not even use the information (such as RCs) available to them because of a sense of social identity threat (Zimbroff, 2005). For example, in more collectivist cultures "standing out", even in a positive sense, may not be perceived as admirable or even desirable. Consequently, information on ever-rising grade point averages or test scores of the average admitted student, typically included (and heavily weighted) in commercial rankings, may prove demoralizing to them (Ibid.). Moreover, at least in the U.S., tests are often impersonal, whereas students from more collectivist cultures generally perform better in personal examinations. This means that they might fail in the application because of reasons not related to "intelligence"'. It is, therefore, possible that potential students stemming from more collectivist cultures do not value the tasks and goals embedded in the college application process and implicitly translated into the information provided in college RCs. In addition, values such as independence, individual achievement, and competition, upheld by much of the college literature, may deviate from collectivist thinking and beliefs (Ibid.). 
When applying these arguments to the development of RCs, one may contend that studying the problem of the indicators used in the rankings solely in the perspective of reliability, validity and comparability may be limiting. Beyond that, it would be interesting to increase our understanding on how these indicators might be interpreted by different social and cultural groups. For example, as mentioned above, indicators such as A-levels or average test scores of incoming classes might be regarded as intimidating by members of collectivist cultures. Hence, their college choice processes might be affected in unexpected ways. Moreover, choosing a college based on the ideal of "personal fit' can be antithetical to some groups' cultural thinking. Indicators such as test scores, high salaries, exit grades, and jobs after graduation, are the embodiment of the "personal fit" principle. It is not suggested here that such indicators ought to be eliminated, but it would be of interest to think of complements to these sorts of indicators. For instance, the future contribution to one's community may be more meaningful to certain people than higher salaries. Another possible indicator which could be useful for different target groups and could conceivably be used in the development of RCs might report information on learning styles (e.g. level of personal guidance, to what extent is the learning based on memorisation, etc.). Other, even basic, information could be added to RCs' content. Information on dietary issues, for example, while very basic, could be important in addressing religious sensitivity. Given the absence of extant studies in the field, such examples are speculative. Well-grounded examples can only developed upon rigorous testing, a worthwhile future research pursuit.

While it would be hard to address all possible target audiences, the use of new technologies may improve the usability and inclusiveness of the information provided by allowing users to create rankings of institutions or programmes that are presented in the clearest way for them and appraise those aspects most important to them (IREG, 2006). It is worth of note, for example, that even the visual display of rankings is "western-centric". Rankings are typically presented in a way that is tailored to the western eye (an issue known as "cultural convention", whereupon all displays are interpreted using common associations of a culture). Thus, for example, increases will be indicated from left to right and clockwise around a circle (Hibbard \& Peters, 2003; Horton, 1993; Kosslyn, 1994; Tufte, 1983). Internet-based RCs in principle allow a great deal of user flexibility, in their ways of presentation.

Research also confirms that issues of habitus (the fit between a student's value and belief system and the academic environment) and cultural capital (support and encouragement by family and community) play decisive roles in students' decision whether and where to apply (Fuligni, 2006; Fuligni \& Hardway, 2004; Fuligni \& Pedersen, 2002; Fuligni, Tseng, \& Lam, 1999; Fuligni \& Witkow, 2004; Nora, 2004).

Yet, as was previously hinted at, rankings address primarily the final phase of college choice (i.e. application/enrolment). However, if RCs took account of the entire process, they would plausibly deal with cultural factors to a greater extent. In fact, it can be argued that the actual college decision is less influenced by cultural elements than earlier phases of the process, when family, peer, and social pressures are strongest. Moreover, while "culture" (unlike socio-economic status) is arguably to some extent self-determined and different groups in society, including students and forthcoming students, undergo a process of acculturation, one must bear in mind that education also influences acculturation. Since education is not actually completed by the time of college choice, it is hard to know to what extent culture is already self-determined for the adolescents and late-adolescents who are in their choice phase. Yet, how rankings could possibly be made more sensitive to the college choice process in its entirety, and to what extent this is feasible (or desirable) remains open to discussion. 
Given that they purport to be tools to assist students in their college choice, it is questionable why RCs should not demonstrate a stronger cultural awareness to be effective in their service towards all "student-customers". For example, a cultural bias might already be present in the selection of data sources. Indicators such as "peer review" (an important indicator in the Times ranking of world universities) are themselves prone to be culturally "biased". Indeed, information provided in the RCs (i.e. the indicators used, and their weights) suggests that cultural determinants are not considered of prime importance. Socio-economic aspects are somewhat taken into consideration, but are not akin to the more specific cultural characteristics mentioned heretofore.

This article has referred to the cultural distinction of individualism vs. collectivism. Of course a pure dichotomy between cultures is not possible and it would be an illegitimate simplification to suggest that so-called "collectivists" will inevitably opt out an achievement framework. U.S. survey research (Zimbroff, 2005) shows a mixed picture in the application process for students from disadvantaged backgrounds (mainly Latino and African American). On the one hand, certain assumptions are not confirmed (e.g. the statement "I'm worried about how I'll fit in with the college crowd at this school" is not seen as problematic, and most disadvantaged respondents value the idea of "being challenged"). Other variables, however, (e.g. "a non-competitive atmosphere", "having high school friends attend", "'a high percentage of peers of the same race, religion, or ethnicity') were rated as critical almost only by students from disadvantaged backgrounds, (which Zimbroff largely attributes to an under-estimation of potential problems and difficulties in the admissions' processes). Moreover, a different approach might be needed for East-Asian cultures. In the U.S. and elsewhere, Asian students are outperforming those from all other cultural backgrounds, especially in mathematical and science fields. Although those cultures are collectivistic, they also put great stress on education, which may largely stem from Confucian learning (Van der Leeuw, 2006). Similarly, other cultural dimensions may have to be included in thinking about design of RCs.

\section{Concluding remarks}

This essay began with the premise that RCs are an increasingly popular instrument in student college choice and that HEIs compete to become ever more attractive to the potential "student-customer". However, a review of classic college choice models suggests that college choice is a long, multi-stage process that can rarely be captured in its entirety by commercial "rankings". Further, recent research suggests that especially cultural factors such as individualistic vs. collectivistic self-construal, values threat, etc. may play a role in students' decision whether and where to apply. In the course of this review we have shown that there is no agreement amongst researchers on RCs' actual effectiveness in reaching out to their purported target audience. We have posited that RCs typically neglect certain cultural determinants that influence college choice behaviour and that therefore they may be of limited value for students. Yet, notwithstanding the litany of comments faced by rankings on other aspects, critiques regarding "culture" are conspicuously lacking. Some possible examples of how RCs could be made more "culturally sensitive" have been presented, even though we concede that these examples are not grounded in extensive primary research. The literature suggests that cultural aspects are an important, albeit under-studied, area in the field of college choice and RCs, but future research is needed to further corroborate our "reasoned speculations". 
Hence, this paper is not presented as conclusive. It has uncovered issues which, as yet, have drawn very limited attention, and that require further research. There is evidence to support claims that "culture" is a critical factor in all aspects of a person's life, including the college choice process and the way one interprets information. Given that RCs aim to provide information to help all students make the best decision on college choice, the study of cultural aspects in the use of RCs is important and has only just begun.

\section{References}

Alwin, D., \& Otto, L. (1977). Higher school context effects on aspiration. Sociology of Education, 50, 259273.

Avery, C., Glickman, M., Hoxby, C., \& Metrick, A. (2004). A revealed preference ranking of U.S. colleges and universities. NBER Working Paper 10803, National Bureau of Economic Research, Cambridge, MA. Retrieved February 25, 2006, from http://www.nber.org/papers/w10803.

Bishop, J. (1977). The effect of public policies on the demand for higher education. Journal of Human Resources, 12, 285-307.

Bowden, R. (2000). Fantasy higher education: University and college league tables. Quality in Higher Education, 6(1), 41-60.

Boyle, R. (1966). The effect of the high school on student aspirations. American Journal of Sociology, 71, 628-639.

Centraal Bureau voor de Statistiek (CBS). (2003). Deelname en slagen in het hoger onderwijs. In Allochtonen in Nederland 2003 (pp. 65-72). Retrieved August 10, 2006, from http://www.cbs.nl/NR/ rdonlyres/0829A30D-FBEE-4B0D-846C-062F06E085D1/0/allochtonennederland03.pdf.

Centraal Bureau voor de Statistiek (CBS). (2007). Jaarboek onderwijs in cijfers 2007. Retrieved January 20, 2007, from http://www.cbs.n1/nr/rdonlyres/2aba48fe-587e-4222-9c63-168a4fc37e66/0/ jaarboekonder wijs2005.pdf.

Chapman, R. (1984). Toward a theory of college choice: A model of college search and choice behavior. Alberta, Canada: University of Alberta Press.

Clarke, M. (2002). Some guidelines for academic quality rankings. Higher Education in Europe, 27(4), 443459.

Dill, D. D., \& Soo, M. (2005). Academic quality, league tables, and public policy: A cross-national analysis of university ranking systems. Higher Education, 49, 495-533.

Eccles, C. (2002). The use of university rankings in the United Kingdom. Higher Education in Europe, $27(4), 423-432$.

Fuligni, A. J. (2006). Family obligation among children in immigrant families. Retrieved August 10, 2006, from http://www.migrationinformation.org/Feature/display.cfm?id=410.

Fuligni, A. J., \& Hardway, C. (2004). Preparing diverse adolescents for the transition to adulthood. The Future of Children, 14, 99-119.

Fuligni, A. J., \& Pedersen, S. (2002). Family obligation and the transition to young adulthood. Developmental Psychology, 38(5), 856-868.

Fuligni, A. J., Tseng, V., \& Lam, M. (1999). Attitudes toward family obligations among American adolescents from Asian, Latin American, and European backgrounds. Child Development, 70, 1030-1044.

Fuligni, A. J., \& Witkow, M. (2004). The postsecondary educational progress of youth from immigrant families. Journal of Research on Adolescence, 14, 159-183.

Fuller, W., Manski, C., \& Wise, D. (1982). New evidence on the economic determinants of post-secondary schooling choices. Journal of Human Resources, 17(4), 472-498.

Goedegebuure, L. C. J., Maassen, P. A. M., \& Westerheijden, D. F. (1990). Quality assessment in higher education. In L. C. J. M. Goedegebuure, A. M. Peter, \& D. F. Westerheijden (Eds.), Peer review and performance indicators: Quality assessment in British and Dutch higher education, Utrecht: Lemma.

Guarino, C., Ridgeway, G., Chun, M., \& Buddin, R. (2005). Latent variable analysis: A new approach to ranking. Higher Education in Europe, 30(2), 147-166.

Hanson, K., \& Litten, L. (1982). Mapping the road to academia: A review of research on women, men, and the college selection process. In P. Perun (Ed.), The undergraduate woman: Issues in education (pp. 73-97) Lexington, MA: Lexington.

Hibbard, J. H., \& Peters, E. (2003). Supporting informed consumer health care decision: Data presentation approaches that facilitate the use of information in choice. Annual Review of Public Health, 24, 413-133.

Hofstede, G. (2003). Culture's consequences, comparing values, behaviors, institutions, and organizations across nations (2nd ed). Sage Publications. 
Horton, W. (1993). Pictures please-Presenting information visually. In C. M. Barnum \& S. Carliner (Eds.), Techniques for technical communicators (pp.187-218). New York: Macmillan.

Hossler, D., Braxton, J., \& Coopersmith, G. (1989). Understanding student college choice. In F. K. Stage, et al. (Eds.), ASHE reader on college students [Review]. Needham Heights, MA: Simon and Schuster.

Hossler, D., \& Gallagher, K. (1987). Studying student college choice: A three phase model and the implications for policy makers. College and University, 2, 207-221.

Hossler, D., Schmit, J., \& Vesper, N. (1999). Going to college. How social, economic and educational factors influence the decisions students make. Baltimore: The Johns Hopkins University Press.

International Ranking Expert Group-IREG (2006). Berlin principles on ranking of higher education institutions. Retrieved August 10, 2006, from http://www.che.de/downloads/Berlin_Principles_ IREG_534.pdf.

Jackson, G. (1982). Public efficiency and private choice in higher education. Educational Evaluation and Policy Analysis, 4:2, 237-247.

Jones, E. D. (2002). Factors that influence the college choice for African American students. Dissertation, Union Institute and University.

Klein, S. P., Kuh, G., Chun, M., Hamilton, L. \& Shavelson, R. (2005). An approach to measuring cognitive outcomes across higher-education institutions. Research in Higher Education, 46(3), 251-276.

Kohn, M., Manski, C., \& Mundel, D. (1976). An empirical investigation of factors which influence collegegoing behavior. Annuals of Economic and Social Measurement, 5(4), 391-419.

Kosslyn, S. M. (1994). Elements of graph design. New York: W.H. Freeman \& Company.

Kroeber A. L., \& Kluckhohn, C. (1952). Culture: A critical review of concepts and definitions. Cambridge, MA: Peabody Museum.

Kühnen, U., Hannover, B, \& Schubert,B. (2001). The semantic-procedural interface model of the self: The role of self-knowledge for context-dependant versus context-independent models of thinking. Journal of Personality and Social Psychology, 80(3), 397-409.

van der Leeuw, K. (2006). Confucianisme: Een inleiding in de leer van Confucius. Amsterdam: Ambo/ Anthos.

Lloyd, T. (Ed.) (2005). College unranked: Ending the college admission frenzy. Cambridge: Harvard University Press.

Mann, L., Radford, M., Burnett, P., Ford, S., Bond, M., Leung, K., et al. (1998). Cross-cultural differences in self-reported decision-making style and confidence. International Journal of Psychology, 33, 325-335.

Manski, C. F., \& Wise, D. A. (1983). College choice in America. Cambridge, MA: Harvard University Press.

March, J. G., \& Simon, H. A. (1958). Organizations, blackwell business. Reprinted in 1993 and 1994. Oxford.

Nora, A. (2004). The role of habitus and cultural capital in choosing a college, transitioning from high school to higher education, and persisting in college among minority and non-minority students. Journal of Hispanic Higher Education, 3, 180-208.

Ohbushi, H.-I., Fukushima, O., \& Tedeschi, J. T. (1999). Cultural values in conflict management: Goal orientation, goal attainment, and tactical decision. Journal of Cross-Cultural Psychology, 30, 51-71.

Polyorat, K., \& Alden, D. L. (2005). Self-construal and need-for-cognition effects on brand attitudes and purchase intentions in response to comparative advertising in Thailand and the United States. Journal of Advertising, Spring 2005.

Provan, D., \& Abercromby, K. (2000). University league tables and rankings: A critical analysis. CHEMS, Paper No. 30. Retrieved February 25, 2006, from http://www.acu.ac.uk/chems/onlinepublications/ 976798333.pdf.

Schramm-Nielsen, J. (2001). Cultural dimensions of decision making: Denmark and France compared. Journal of Managerial Psychology, 16(6), 401-423.

Spencer-Oatey, H. (2000). Culturally speaking: Managing rapport through talk across cultures. London: Continuum.

Tufte, E. R. (1983). The visual display of quantitative information. Cheshire, CT: Graphics.

Usher, A., \& Savino, M. (2006). A world of difference: A global survey of University league tables. Retrieved February 25, 2006, from Educational Policy Institute, Canadian Education, Report Series, http://www.educationalpolicy.org/worlddifference.html.

Vaughn, J. (2002). Accreditation, commercial rankings, and new approaches to assessing the quality of university research and education programmes in the United States. Higher Education in Europe, 27(4), 433-443.

Vossensteyn, H. (2005). Perceptions of student price-responsiveness. Dissertation, Center for Higher Education Policy Studies. The Netherlands: University of Twente.

Zimbroff, J. A. (2005). Policy implications of culturally based perceptions in college choice. Review of Policy Research, 22(6), 811-840. 